\title{
Study of near miss cases in obstetrics and maternal mortality in Bastar, Chhattisgarh, India
}

\author{
Mamta Bansal*, Jyoti Lagoo, Khushbu Pujari \\ Department of Obstetrics and Gynecology, Late B. R. K. M. Govt Medical College, Bastar, Chhattisgarh, India
}

Received: 03 February 2016

Accepted: 13 February 2016

\section{*Correspondence:}

Dr. Mamta Bansal,

E-mail: drmamtabansal1812@gmail.com

Copyright: $\odot$ the author(s), publisher and licensee Medip Academy. This is an open-access article distributed under the terms of the Creative Commons Attribution Non-Commercial License, which permits unrestricted non-commercial use, distribution, and reproduction in any medium, provided the original work is properly cited.

\begin{abstract}
Background: According to millennium development goals (MDG) in 2015, the goal number five was to improve the maternal health is falling way below our target. Our aim in reducing maternal mortality by $75 \%$ has not been met with MDG. Pregnant women's health status is not reflected by mortality indicators alone hence the concept of severe acute maternal morbidity (SAMM) is an apt for the present health providing system. The main objectives of the study were to; (1) To determine the frequency of maternal near miss, maternal near miss incidence ratio (MNMR), maternal near miss to mortality ratio and mortality index; (2) To compare the nature of near miss events with maternal mortality; (3) To observe the trend of near miss events.

Methods: It was a retrospective study design conducted at Late B.R.K.M Government medical college, Jagdalpur, Chhattisgarh, India during September 2013 to August 2014. The study population includes near miss cases and maternal deaths. Cases were defined based on WHO criteria 2009.

Results: Out of 3539 deliveries, 39 wear near miss cases during the study period. The maternal near miss incidence ratio was $11.9 / 1000$ live births, maternal near miss to mortality ratio was $2.05: 1$, and mortality index was $32.7 \%$. Hemorrhage was the leading cause (43.5\%), followed by severe anemia (15.38\%), rupture uterus (15.38\%), preeclampsia/eclampsia $(12.82 \%)$, sepsis $(5.12 \%)$, complicated malaria $(5.12 \%)$ and hepatitis $(2.56 \%)$. Maternal mortality ratio (MMR) was 580/100000 live births.

Conclusions: Hemorrhage was the leading cause of near miss events. As near miss analysis indicates the quality of health care, it is worth presenting in national indices.
\end{abstract}

Keywords: Maternal near miss, Maternal mortality, Mortality index, Haemorrhage, Severe anemia

\section{INTRODUCTION}

According to millennium development goals (MDG) in 2015 , the goal number five was to improve the maternal health is falling way below our target. Our aim in reducing maternal mortality by $75 \%$ has not been met with MDG. ${ }^{1}$ Pregnant women's health status is not reflected by mortality indicators alone hence the concept of severe acute maternal morbidity (SAMM) is an apt for the present health providing system. ${ }^{2,3}$ SAMM has been studied extensively in the recent past as a complement for maternal mortality and also to evaluate the quality of obstetric care in that particular institution. This concept is superior over maternal death in drawing attention to surviving women's reproductive health and lives and is equally applicable in developing countries as well as developed countries. In many developed countries, maternal mortality has fallen to single digits whereas near miss cases are more and hence useful in evaluation of the present system. Moreover, they have the advantage of not being as rare as maternal deaths for providing adequate information, as well as still being rare enough not to overload clinicians and data collection personnel within the facility. ${ }^{4}$ Till recently there were no criteria set for identification of these cases for routine implementation, and wider application of this concept was limited. ${ }^{5}$ But in 
2009, WHO has come up with clinical, laboratory, and management criteria for the identification of these cases. ${ }^{6}$ Maternal near miss case is defined as "a woman who nearly died but survived a complication that occurred during pregnancy, childbirth, or within 42 days of termination of pregnancy", 6

In our study, we aimed to determine the frequency of maternal near miss, MNM incidence ratio (MNRM), maternal near miss to mortality ratio, and mortality index. Our second objective was to analyse the nature of near miss events and compare the causes of near-miss cases with that of maternal mortality. We had also observed the trend of near-miss events and maternal deaths in one year.

\section{METHODS}

A retrospective analysis of data collected from September 2013 to August 2014. Ours is a tertiary care centre covering around $200 \mathrm{kms}$ of tribal area of Chhattisgarh, India. It is a referral centre for both private and public hospital in Bastar, India and surrounding districts.

Potentially life threatening conditions were diagnosed and those cases which met WHO 2009 criteria were selected. Maternal mortality during the same period was also analysed. Patients were categorised by final diagnosis with respect to hemorrhage, hypertension and sepsis etc. as direct causes whereas anemia and other medical disorders were considered as indirect causes contributing to maternal near miss and death.

Following indices were calculated

1. Maternal near miss incidence ration per 1000 live births.

2. Maternal near miss and mortality ratio

3. Mortality index $-\frac{M D}{M N M+M D} \times 100$

4. Maternal mortality rate

\section{RESULTS}

During the one year study period, a total no. of admission were 5026, 3539 were total no of deliveries and total no of live births were 3276. Out of which near miss cases were 39 and 19 cases were of maternal death.

Table 1 shows $41.02 \%$ of near miss cases were found in $18-24$ year of age group while $47.36 \%$ cases of maternal death were found in 25-30 year of age group. Multipara cases were slightly more in near miss cases while primipara was slightly more in maternal death cases. Majority of the patients were in third trimester in both near miss cases $(56.41 \%)$ and maternal death groups $(63.15 \%)$ respectively.

Among the causes of near miss events, hemorrhage was the leading cause with $43.5 \%$, followed by severe anemia $(15.38 \%)$ and rupture uterus $(15.38 \%)$ whereas preeclampsia/eclampsia (31.57\%) was the leading cause of maternal mortality in our set up followed by sepsis $(15.78 \%)$ and severe anemia (15.78\%). It is important to note that mortality index was high in our setup with highest for hepatitis $(66.67 \%)$ followed by sepsis $(60 \%)$.

Table 1: Characteristics of near miss cases and maternal deaths.

\begin{tabular}{|lccll|}
\hline Characteristics & $\begin{array}{l}\text { Near miss } \\
\text { cases } \\
(39)\end{array}$ & & $\begin{array}{l}\text { Maternal } \\
\text { death } \\
(19)\end{array}$ & \\
\hline Age & & & & \\
\hline 18-24 Years & 16 & 41.02 & 08 & 42.10 \\
\hline 25-30 Years & 12 & 30.76 & 09 & 47.36 \\
\hline 31-36 Years & 01 & 2.56 & 02 & 10.52 \\
\hline Parity & & & & \\
\hline Primipara & 14 & 35.89 & 11 & 57.89 \\
\hline Multipara & 25 & 64.10 & 08 & 42.10 \\
\hline Gestational age in weeks & & & \\
\hline 01-12 & 02 & 5.12 & Nil & - \\
\hline 13-28 & 03 & 7.69 & 03 & 15.79 \\
\hline$>28$ & 22 & 56.41 & 12 & 63.15 \\
\hline Post Natal & 12 & 30.76 & 04 & 21.05 \\
\hline
\end{tabular}

Table 2: Comparison of near miss events and primary causes of maternal deaths.

\begin{tabular}{|c|c|c|c|c|c|c|}
\hline Causes & $\begin{array}{l}\text { Near miss } \\
\text { cases } \\
\mathrm{N}=39\end{array}$ & Percentage & $\begin{array}{l}\text { Near miss } \\
\text { cases in } 1000 \\
\text { live birth }\end{array}$ & $\begin{array}{l}\text { Maternal } \\
\text { mortality } \\
\mathrm{N}=19\end{array}$ & Percentage & $\begin{array}{l}\text { Mortality index } \\
\frac{M D}{M N M+M D} \times 100\end{array}$ \\
\hline Haemorrhage & 17 & $43.5 \%$ & 5.18 & 1 & $05.26 \%$ & 5.56 \\
\hline Pre-eclampsia/ eclampsia & 05 & $12.82 \%$ & 1.52 & 06 & $31.57 \%$ & 54.5 \\
\hline Sepsis & 02 & $05.12 \%$ & 0.61 & 03 & $15.78 \%$ & 60 \\
\hline Rupture uterus & 06 & $15.38 \%$ & 1.83 & Nil & & 0 \\
\hline Malaria $\mathrm{PFR}^{+\mathrm{ve}}$ & 02 & $05.12 \%$ & 0.61 & 02 & $10.52 \%$ & 50 \\
\hline Hepatitis & 01 & $02.56 \%$ & 0.3 & 02 & $10.52 \%$ & 66.67 \\
\hline Severe anemia & 06 & $15.38 \%$ & 1.83 & 03 & $15.78 \%$ & 33.3 \\
\hline Diarrhoea with shock & Nil & & & 02 & $10.52 \%$ & - \\
\hline
\end{tabular}




\section{DISCUSSION}

This is the first attempt to document both maternal near miss and mortality in Bastar region, India. The maternal near miss incidence ratio (MNMR) was 11.9/1000 live births in our hospital. Studies shows the similar trend and varies between 15-40/1000 live births in the developing countries. ${ }^{6-8}$ The above studies have used various criteria for identification of the cases. A cross-sectional study done in Brazil using the Mantel's and Waterson's criteria has shown a varying pickup rate of 62 and 86, respectively. ${ }^{9}$ So some variation in the pickup rate from other studies might be there with the WHO criteria.

The maternal mortality ratio at our setup was 580/100000 live births. The Brazilian study showed a mortality rate of $260 / 100000$ live births. ${ }^{8}$ In other developing countries the maternal mortality ratios were $423 / 100000$ live births and $324 / 100000$ live births. ${ }^{10,1}$

Most common initiating conditions leading to maternal near miss were hemorrhage $(43.5 \%)$, severe anemia (15.38\%), rupture uterus $(15.38 \%)$, preeclampsia/ eclampsia (12.82\%), sepsis (5.12\%), complicated malaria $(5.12 \%)$ and hepatitis $(2.56 \%)$. Results were in accordance with other studies. ${ }^{12-14}$ Most of the studies were done before WHO criteria, so there may be variation in picking up of cases.

A total 19 deaths were observed in our study. The main leading cause was preeclampsia/eclampsia (37.57\%). Most of the patient of maternal death group came to our hospital at terminal stage and died within 10-12 hours.

Maternal mortality index $\left(\mathrm{MI}=\frac{M D}{M N M+M D} \times 100\right)$ in our setup is 32.7 . This is very high. Near miss to mortality ratio was 2.05:1 which means for every 2-3 life threatening conditions there was one maternal death. Syrian study showed a ratio of 60:1 and study done in Nepal showed a ratio of 7.2:1. ${ }^{10,11}$ This ratio is similar to those of African country where the range is $5-12: 1 .{ }^{9}$ The study of Manipal shows 5.6:1. ${ }^{15}$

Ours is tertiary referral centre covering remote and tribal areas of Chattisgarh, in and around Bastar, India. Our setup is serving around $200 \mathrm{~km}$ of area where most of the population is tribal and illiterate and most of the areas are not connected directly by road which is why most of the cases are referred in already moribund state.

The higher the mortality index, more the women with the life threatening conditions dies (low quality of care), while low index suggests better quality of health care. The high mortality index in our centre is due to inadequate utilization of resources, poor antenatal care, delayed referrals, poor transport facilities and lack of skilled personnel at sub centre, PHC and CHC levels.

\section{CONCLUSION}

Near miss cases share many characteristics with maternal deaths and can directly inform about obstacles that had to be overcome after the onset of an acute complication, hence providing valuable information on obstetric care. This allows for corrective action to be taken on identified problems to reduce related mortality and long-term morbidity. Based on our findings, we recommend a number of government actions to avert future maternal deaths as following; (1) Improving antenatal care to help early identification of high risk pregnancies including pre-eclampsia; (2) Developing protocols to prevent/ manage post-partum haemorrhage including raising the awareness about using active management during third stage; (3) Training obstetric health professionals on managing infrequent but fatal conditions like sepsis; (4) Urgently reviewing the referral system and emergency obstetric care in Bastar, India.

Funding: No funding sources Conflict of interest: None declared

Ethical approval: This study was ethically approved by ethical committee of Late B.R.K.M. Govt medical college

\section{REFERENCES}

1. Nielsen HS, Eggebo TM. Millenium development Goal 5- an obstetric challenge. Acta Obstetricia et Gynecologica Scandinavica. 2012;91(9):1007-8.

2. Stones W, Lim W, Al-Azzawi F, Kelly M. An investigation of maternal morbidity with identification of life-threatening "near miss" episodes. Health Trends. 1991;23(1):13-5.

3. Sivalingam N, Looi KW. Clinical experience with management of near-miss cases in obstetrics. Medical Journal of Malaysia. 1999;54(4):496-503.

4. Pattinson RC, Vandecruys HI, Macdonald AP, Mantel GD. Why do women die during childbirth. http://scienceinafrica.com/old/index.php?q=2001/aug ust/mothers. htm.

5. Say L, Pattinson RC, "ulmezoglu AMG. WHO systematic review of maternal morbidity and mortality: the prevalence of severe acute maternal morbidity (near miss). Reproductive Health. 2004;1(1);10-9.

6. Say L, Souza JP, Pattinson RC. Maternal near miss towards a standard tool for monitoring quality of maternal health care. Best Practice and Research. 2009;23(3):287-96.

7. van Roosmalen J, Zwart J. Severe acute maternal morbidity in high-income countries. Best practice and research: Clinical Obstetrics and Gynaecology. 2009;23(3):297-304.

8. Souza JP, Cecatti JG, Parpinelli MA, Serruya SJ, Amaral E. Appropriate criteria for identification of near-miss maternal morbidity in tertiary care facilities: a cross sectional study. BMC Pregnancy and Childbirth. 2007;7(20):1-8. 
9. Prual A, Huguet D, Garbin O, Rab'e G. Severe obstetric morbidity of the third trimester, delivery and early puerperium in Niamey (Niger). African Journal of Reproductive Health. 1998;2(1);10-9.

10. Shrestha NS, Saha R, Karki C. Near miss maternal morbidity and maternal mortality at Kathmandu Medical College Teaching Hospital. Kathmandu University Medical Journal. 2010;8(30):222-6.

11. Almerie Y, Almerie MQ, Matar HE, Shahrour Y, Al Chamat AA, Abdulsalam A. Obstetric near-miss and maternal mortality in maternity university hospital, Damascus, Syria: a retrospective study. BMC Pregnancy and Childbirth. 2010;10(65):2-7.

12. Baskett TF, Sternadel J. Maternal intensive care and near-miss mortality in obstetrics. $\mathrm{Br} \mathrm{J}$ Obstet Gynecol. 1998;105:981-4.

13. Mantel GD, Buchmonn E, Rees H, Pattinson RC. Severe acute maternal morbidity: a pilot study of a definition for a near-miss. Br J Obstet Gynecol. 1998;105:985-90.

14. Sivalingam N, Looi KW. Clinical experience- with management of near miss cases in obstetrics. Med J Malaysia. 1999;54:496-503.

15. Ps R, Verma S, Rai L, Kumar P, Pai MV, Shetty J. "Near miss" obstetric events and maternal deaths in a tertiary care hospital: an audit. J Pregnancy. 2013;2013:393758.

Cite this article as: Bansal M, Lagoo J, Pujari K. Study of near miss cases in obstetrics and maternal mortality in Bastar, Chhattisgarh, India. Int J Reprod Contracept Obstet Gynecol 2016;5:620-3. 